\title{
RISCO DE EROSÃO NO LITORAL NORTE DE PORTUGAL: UMA QUESTÃO DE ORDENAMENTO DO TERRITÓRIO
}

\author{
Risk of erosion on the northern coast of Portugal: \\ a question of territorial planning
}

\author{
António de Sousa Pedrosa \\ Prof. Associado, Depto de Geografia, Fac. de Letras da Universidade do Porto, CEGOT, Portugal \\ Bolsista CAPES, Brasil \\ aspedros@gmail.com
}

Artigo recebido em 16/05/2012 e aceito para publicação em 01/08/2012

RESUMO: Grande parte da costa noroeste de Portugal Continental apresenta várias áreas em erosão acentuada, fato que tem contribuído para um agravamento da vulnerabilidade do território.

Entendendo a faixa costeira uma área de interface entre os subsistemas terra-mar, constitui uma área dotada de grande mutabilidade, que se encontra em conflito com o atual cariz permanente da presença humana, pelo que a fragilidade tem a sua maior expressão na erosão e no recuo da linha de costa, fenómeno que tem vindo a resultar na perda de áreas de valor ecológico-ambiental e económico.

Esta situação resulta de diversos fatores naturais que se relacionam com a subida do nível médio das águas do mar, mas também da atuação do homem sobre o território. A atuação antrópica nas áreas litorais nem sempre obedece a princípios de sustentabilidade ambiental e económica, fato explicado pela inexistência de uma estratégia bem definida de ordenamento do território.

Apresentando-se como áreas de forte sensibilidade à ação antrópica, em especial relacionado com a pressão urbanística e, à implantação de infraestruturas relacionadas com o turismo e lazer, para além de estarem sujeitas a uma forte suscetibilidade de erosão provocada pelo avanço do mar, a forma de mitigação dos riscos seria a existência de planos de ordenamento que definissem uma estratégia de desenvolvimento não agressiva para as zonas de litoral em Portugal.

Palavras-chave: Litoral Norte de Portugal, risco de erosão, ação antrópica, planeamento territorial, ocupação do litoral.

ABSTRACT: Part of the northwest coast of Portugal, comprises several areas marked erosion, a fact that has contributed to an increase of the vulnerability of the territory.

Understanding the coastal strip an area of interface between the subsystems land-sea, is an area with high mutability, which is in conflict with the current nature of the permanent human presence, so that fragility has its highest expression in the erosion and retreat of the coastline, a phenomenon that has meant the loss of areas of high ecological and economic.

This results from several natural factors relating to the rise in the average level of the sea, but also of anthropogenic activities on the territory. The action of man in the coastal areas, does not always obey the principles of environmental and economic sustainability, which is explained by the absence of a clear strategy of spatial planning.

Presenting itself as areas of high sensitivity to human action, especially related to urban pressure and the implementation of infrastructure related to tourism and leisure, in addition to being subject to a strong susceptibility to erosion caused by the advancing sea, way of mitigating the risks would be the existence of development plans, which define a non-aggressive development strategy for coastal areas in Portugal. Keywords: North Coast of Portugal, erosion risk, human action, territorial planning, occupation of the coast. 


\section{INTRODUÇÃO: O LITORAL NW DE PORTU- GAL}

A costa noroeste de Portugal Continental (Espinho-Caminha) caracteriza-se pela existência de plataforma litoral de dimensão variável cuja ligação ao maciço Hespérico se faz através de uma arriba fóssil que coincide em muitos locais com uma escarpa de falha com demonstração de atividade tectónica ao longo do Quaternário.

Sobre a plataforma litoral existe um grande número de depósitos cenozóicos assentes sobre as rochas do paleozóico. Estes depósitos foram geralmente considerados como praias levantadas na literatura até aos anos oitenta. No entanto estudos mais detalhados sobre o ponto de vista sedimentológico permitiram determinar dois grandes grupos: aqueles que se localizam a acima dos 50m mais antigos e de origem fluvial (ARAÚJO, 2000, 2001) e os que se situam abaixo dos $40 \mathrm{~m}$ de caráter claramente marinho (que poderiam também designar-se como terraços marinhos ou praias levantadas, de acordo com a designação clássica que lhes foi, muitas vezes, atribuída). A separação destes dois tipos de depósitos faz-se sempre, por meio de um degrau topográfico, bastante nítido, que se situa entre os $37 \mathrm{~m}$ e os $60 \mathrm{~m}$ e acima do qual se encontra a generalidade dos depósitos de fácies fluvial.
A separação clara entre estes dois tipos de depósitos e a existência de diversos acidentes de tectónica recente, afetando os depósitos de fácies fluvial, sugerem que este degrau corresponda a uma falha de direção submeridiana ao longo da qual o sector ocidental terá abatido num período posterior à formação dos depósitos fluviais de fácies torrencial (ARAÚJO, 2000, 2001).

Os diferentes níveis que podem ser interpretados na plataforma litoral, a presença da arriba fóssil e a análise sedimentológica transmitem, segundo A. Araújo (1985, 2000), Granja (1999); G. Carvalho, H. Granja, E. Loureiro, R. Henriques (2006) J. Dias, P. Bernardo, R. Bastos (2002), indicações importantes acerca da atuação de episódios de transgressão e regressão marinhas mais ou menos significativas no passado. J. Dias (1989) apresenta uma proposta da evolução geral da linha de costa em Portugal Continental (figura. 1), que sugere a presença desta, em períodos recuados, bem mais para o interior do oceano Atlântico do que atual posição da linha de costa. Como se observa, os ciclos de avanço e recuo da linha de costa parecem ter coincidido com os diferentes períodos climáticos abrangendo uma escala temporal alargada (RODRIGUES, MAGALHÃES \& DIAS, 1991).

Deste modo, o recuo da linha de costa não é de todo um fenómeno novo, embora as intervenções antrópicas recentes, diretas ou indiretas, estejam a contribuir para que o atual recuo se faça de uma forma mais acelerada.

Figura 1. Evolução da Linha de Costa do NW de Portugal nos últimos $16000 \mathrm{BP}$

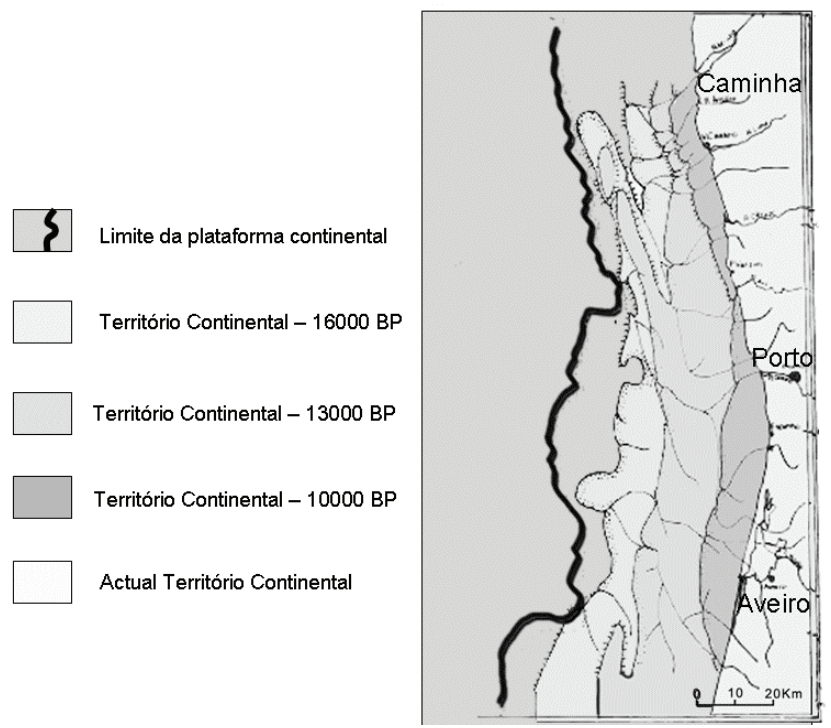

Fonte: Adaptado de J. Dias, 1989. 


\section{OS FATORES DE EVOLUÇÃO DA LINHA DE COSTA}

A constituição geológica da linha de costa, o diferente grau de resistência e de fragilidade de cada tipo de rocha aos vários agentes erosivos, explicam em parte a fisionomia da costa litoral. O tipo de clima e as condições de agitação marítima constituem importantes agentes de atuação sobre as formas do litoral.

Nesta costa domina uma ondulação de WNW $(88,4 \%)$ e NW (42,4\%), e apresenta caraterísticas que potenciam a sua ação erosiva. A ondulação tem origem no Atlântico Norte, a latitudes mais elevadas, com uma altura superior a $1 \mathrm{~m}$ durante $95 \%$ do ano, podendo atingir ondas de $4 \mathrm{~m}$ em $5 \%$ dos dias. De realçar que nos meses de Outono e Inverno podem prevalecer alturas máximas de $8 \mathrm{~m}$ a $11 \mathrm{~m}$ e períodos de $8 \mathrm{~s}$ de intervalo entre as ondas o que representa uma propensão para a existência de uma forte susceptibilidade á erosão das praias (CARVALHO \& BARCELÔ, 1966; COELHO, 2005). No inverno e nos períodos de transição este tipo de ondulação pode ocorrer devido fundamentalmente à circulação do ar de NW pós-frontal. De acordo com M. Costa, R. Silva, J. Vitorino (2001) na costa oeste de Portugal Continental $75 \%$ dos temporais que ocorrem têm uma duração inferior a 2 dias, independentemente do setor costeiro em análise e concluíram que os temporais com duração superior a 2 dias estão associados preferencialmente a direções de NW. Quando as durações dos temporais é superior a 5 dias, a sua proveniência relaciona-se sempre com a direção referida.

A costa ocidental portuguesa enquadra-se no domínio meso-mareal, ocorrendo duas marés com uma periodicidade de $12 \mathrm{~h} 25 \mathrm{~m}$, sendo o valor máximo teórico de preia-mar de marés vivas de cerca de $4 \mathrm{~m}$, com propagação no sentido Sul-Norte (BARBOSA et al., 2003). A ocorrência de temporais nesta costa pode ocasionar o aparecimento de marés meteorológicas, nas quais a sobre-elevação das águas do mar é o resultado da diminuição da pressão atmosférica junto à superfície do oceano ou à ação de ventos fortes e persistentes. São poucos os estudos desenvolvidos neste âmbito, mas segundo dados avançados pelo LNEC (1996) foram já registadas sobre-elevações de $10,4 \mathrm{~m}$ a 31 de Dezembro de 1981 e $10,2 \mathrm{~m}$ a 7 de
Novembro de 1982, na costa ocidental portuguesa (valores obtidos na bóia de Leixões-Matosinhos), sendo os valores mais frequentes os de $+1,5 \mathrm{~m}(\mathrm{ZH}) \mathrm{e}$ $+2,7 \mathrm{~m}(\mathrm{ZH})$. Os efeitos da ondulação podem ser ainda potenciados pelo tipo de maré astronómica presente durante a sua ocorrência.

No entanto, apesar de costa NW de Portugal ser uma área onde os fatores naturais, implicam uma forte susceptibilidade á erosão costeira, o fenómeno em si e o consequente recuo da linha de costa resulta de um vasto conjunto de fatores indutores, que embora sendo na sua maioria naturais, são, muitas vezes, despoletados direta ou indiretamente pela atuação antrópica, de entre os quais J. Dias et al (1994) destaca: i) elevação do nível médio do mar; ii) diminuição da quantidade de sedimentos fornecidos ao litoral; iii) degradação antrópica das estruturas naturais; iv) obras pesadas de engenharia costeira.

A faixa litoral tem um comportamento variável no tempo e no espaço desde a macro à micro-escala. Partindo de diversos vestígios arqueológicos e geológicos encontrados ao longo da costa noroeste de Portugal Continental, é possível observar-se períodos em que a linha de costa migrou no sentido do mar, interrompidos por períodos em que migrou no sentido do continente (DIAS et al, 1994), tal como aconteceu na época Romana e na Idade Média. Estes períodos têm vindo a ser associados a oscilações climáticas positivas, embora com reservas, uma vez que os estudos neste âmbito são muito escassos em Portugal. $\mathrm{Na}$ atualidade os estudos desenvolvidos (DIAS \& TABORDA, 1988; DIAS, 1990, 2005; GRANJA, 1999; CARVALHO et al., 2002; COELHO, 2005; MARTINS et al., 2005; CARVALHO, 2006); têm demonstrado que o nível médio das águas do mar se encontra em fase de subida, provocado pela tendência de um certo acréscimo das temperaturas a nível mundial, que provocam o degelo das calotes polares e a consequente subida das águas oceânicas.

No entanto, a atuação antrópica sobre o território possui consequências indubitáveis, ao nível do processo erosivo, que se verifica na linha de costa portuguesa, nomeadamente no seu sector NW.

A construção de aproveitamentos hidroelétricos e hidroagrícolas têm contribuído para uma redução acentuada da quantidade de sedimentos fornecidos ao 
litoral, em especial a partir da década de cinquenta do século passado. Na bacia hidrográfica do rio Douro que abrange uma grande parte do território da Península Ibérica e do Norte de Portugal em particular, foram construídas 53 barragens desde 1930 em território nacional e 97 em Espanha, fato que implica alterações profundas na dinâmica fluvial deste rio, nomeadamente no que se refere ao transporte de sedimentos, em carga de fundo ou em suspenção. Contudo, no Norte de Portugal não foi a única bacia hidrográfica que sofreu alterações na sua dinâmica, já que outras, de menores dimensões, também apresentam vários exemplos de construção de barragens, que ao impedirem a livre circulação de sedimentos fluviais, são responsáveis pela retenção de mais de $80 \%$ do volume de areias em circulação, que deixaram de alimentar as praias da costa NW de Portugal (DIAS et al, 1994).

Todavia, a intervenção antrópica pode ser ainda mais intensa no litoral através da destruição das estruturas naturais de defesa costeira, em especial o cordão dunar frontal e das dunas. $\mathrm{O}$ turismo balnear, o avanço da urbanização e a construção de áreas industriais são as principais atividades que têm como consequência a criação de corredores eólicos, a alteração dos planos de escorrência e a exploração intensa de sedimentos deixando áreas depressionárias de fácil inundação. Deste modo, a ação das ondas e das marés terão consequências ainda mais graves e por vezes irreversíveis, sobretudo, quando a capacidade de auto-recuperação dos perfis de praia e das dunas após as tempestades se torna irrecuperável. Devido á destruição destas estruturas, a vulnerabilidade da ocupação humana a galgamentos oceânicos passou a ser muito maior, cuja consequência foi a construção de estruturas pesadas de engenharia, com o finalidade de proteger as povoações do avanço do mar. As principais estruturas encontradas ao longo da costa noroeste de Portugal Continental são os quebramares, os esporões e as estruturas longilitorais. Contudo, este tipo de intervenção provoca um desequilíbrio na circulação natural dos sedimentos ao longo do litoral, tendo como principal consequência a acumulação sedimentar a norte das estruturas e o agravamento da erosão a sul (figura 2 / figura 3), fato que se explica por uma predominância da deriva marítima de NW na costa em questão.

Figura 2. Esquema das consequências resultantes da construção de esporões ou quebra-mares no litoral
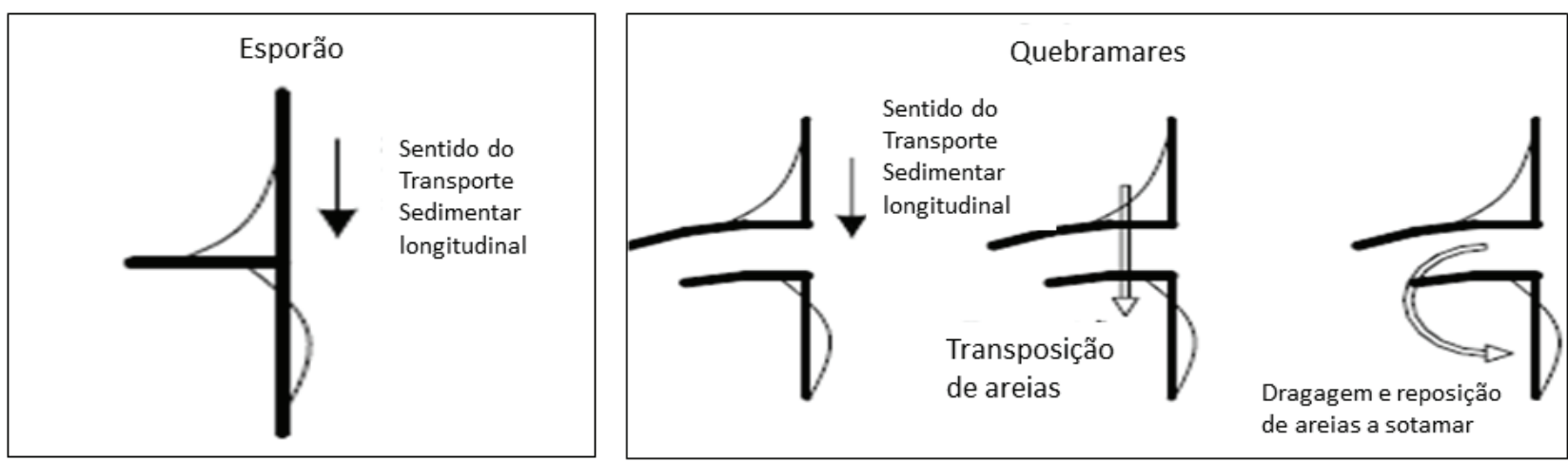

Fonte: Adapatado de Coelho, 2005. 
Figura 3. Efeitos de erosão imediatamente a sul do esporão de Cortegaça.

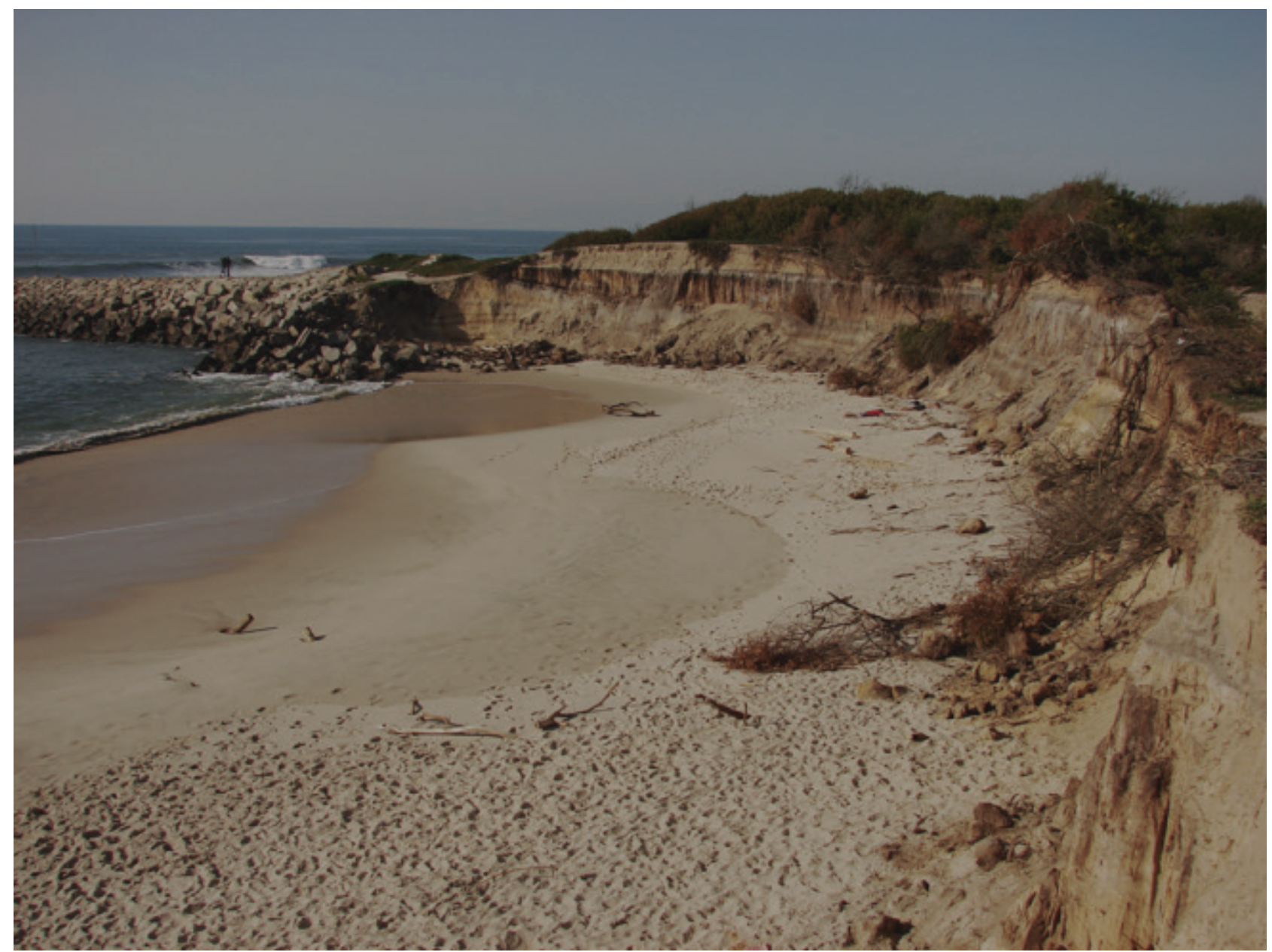

Fonte: Pedrosa, 2007.

Apesar da sua eficácia a curto e médio prazo na estabilização da linha de costa, estas estruturas revelam-se frágeis com o tempo, exigindo investimentos e intervenções de recuperação e reposição da segurança, que vão sendo progressivamente cada vez mais elevados.

Grande parte da costa noroeste de Portugal Continental compreende várias áreas em erosão acentuada, fato que tem vindo a contribuir para um agravamento da vulnerabilidade do território. Esta situação torna-se ainda mais problemática quando se verifica que a crescente ocupação e exploração das zonas costeiras, nas últimas décadas, têm-se desenvolvido numa base de nem sempre obedecer a princípios de sustentabilidade ambiental e económica. As zonas costeiras são áreas bastante sensíveis à ação antrópica, em especial a pressão urbanística, à implantação de infraestruturas relacionadas com o turismo e o lazer e à desestruturação funcional das comunidades costeiras.

Em resultado da pressão de crescimento e consolidação da construção no litoral, o paradigma de desenvolvimento socioeconômico pelo qual se optou nas últimas décadas, premiou uma estratégia de manutenção e, em muitos casos, de densificação do edificado nas frentes marítimas. Esta estratégia implicou, por parte dos municípios com frente marítima, a construção de estruturas de engenharia pesadas, com o objetivo de proteger as construções contra as ações erosivas do mar. As implicações desta politica são desastrosas por diversas razões: $i$ ) em termos 
financeiros, já que o capital aplicado na construção destas infraestruturas não pode ser considerado um investimento, mas sim um custo; ii) em termos ambientais, já que alteram radicalmente a dinâmica marítima natural, contribuindo para a destruição, cada vez mais rápida, das praias e dos sistemas dunares: iii) em termos estéticos, já que possuem implicações visuais na paisagem litoral o que prejudica as atividades relacionados com o turismo.

\section{A (IN) SUSTENTABILIDADE DO LITORAL: UMA QUESTÃO DE ORDENAMENTO DO TERRITÓRIO}

A concentração de população no litoral português, em especial a partir da década de setenta, promoveu o desenvolvimento de atividades económicas relacionadas com os sectores secundário e terciário. $\mathrm{O}$ rápido crescimento demográfico, a presença crescente de atividades económicas e as importantes mudanças político-administrativas dos espaços litorais, provocaram a sua "sobrecarga", com padrões de ocupação do solo muito distintos dos que se observavam antes da década de setenta e, com uma crescente exposição das populações e do património aos riscos naturais, em especial ao risco das atuações energéticas do mar e da erosão costeira (CARDOSO, 2007; PEDROSA (coord), 2007; PEDROSA \& FREITAS, 2008a, 2008b; BASTO. 2010).

A figura 4 demonstra claramente o avanço da urbanização na área compreendida entre Aver-o-mar e Póvoa de Varzim (1958 - 2001) fato que aconteceu de uma forma muito rápida, principalmente nos últimos quinze anos do século XX. Nota-se uma completa artificialização da área litoral tendo sido ocupados e destruídos todos os ambientes de dunas, diversas áreas agrícolas e mesmo espaços de praia (CARDOSO, 2005).Porém, a erosão costeira não é um fenómeno atual, já que em períodos históricos recentes, o recuo da linha de costa e as consequências sobre as propriedades fizeram-se sentir de forma bem evidente, como foi possível analisar em Espinho com base na recolha de notícias locais e em monografias (PEDROSA \& FREITAS, 2008a).

Figura 4. Evolução espaço-temporal de Aver-o-mar e Póvoa de Varzim (1958-2001).
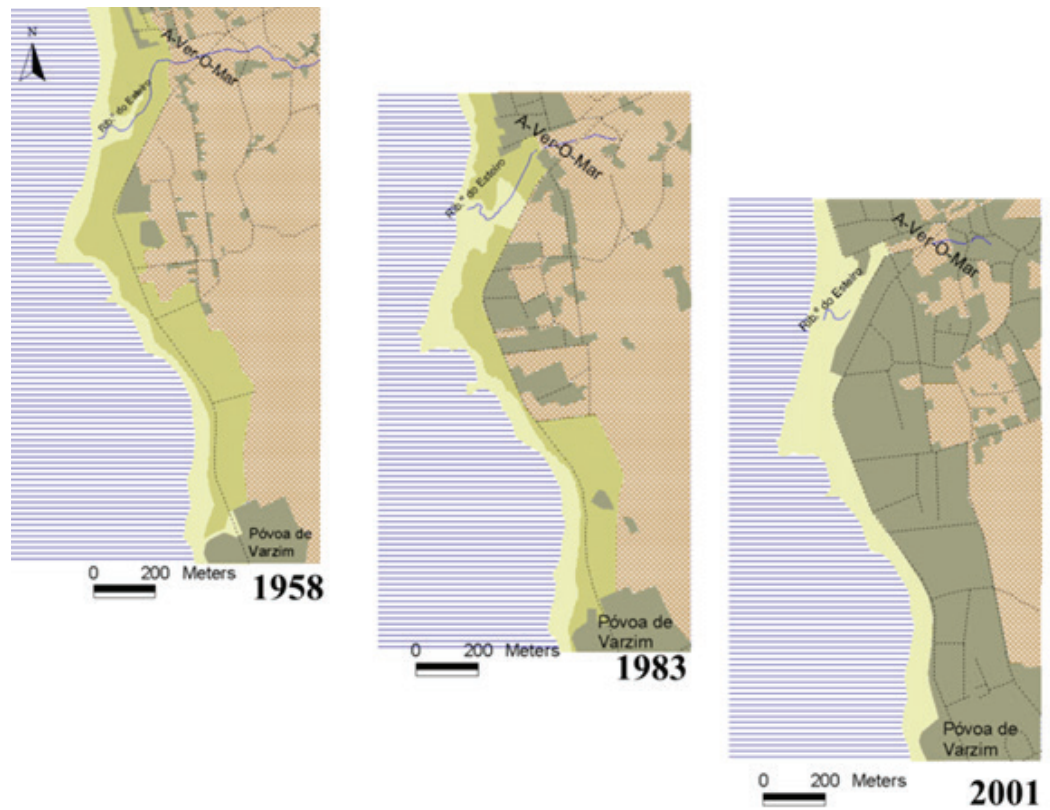

Vias de comunicaçăo Cursos de água Estufas

Espaços urbanos e recreativos Espaços agricolas Espaços de praia Oceano

$\widehat{N}$ Enrocamentos

Fonte: A, Cardoso, 2005 
As preocupações com este fenómeno tornaram-se mais expressivas após a década de setenta e, em especial durante a década de oitenta do século passado, período em que a construção de estruturas pesadas de proteção costeira proliferou ao longo de toda a costa portuguesa, como a solução mais viável e duradoura de proteção das frentes marítimas, que se apresentavam cada vez mais urbanizadas e vulneráveis. De fato, durante este período de tempo, as intervenções no litoral português eram da responsabilidade das autarquias, não existindo nenhum organismo nacional com a responsabilidade no seu planeamento e monitorização (PEREIRA \& FREITAS, 2008).

Assim o modelo de ocupação do litoral no Norte de Portugal processou-se de uma forma caótica, desenvolvendo-se de uma forma tentacular e linear, envolvendo faixas adjacentes aos núcleos urbanos primitivos, inicialmente ocupados por dunas frontais, espaços interdunares e agrícolas, ou seja, o contrário do modelo idealizado pelo INAG (1994) para a ocupação de áreas litorais com o intuito de minimizar os riscos do avanço do mar (figura 5).

Figura 5. Modelo do INAG, de ocupação das áreas de risco para o litoral português

OCUPAÇÃO DE ÁREAS DE RISCO

Situação Actual

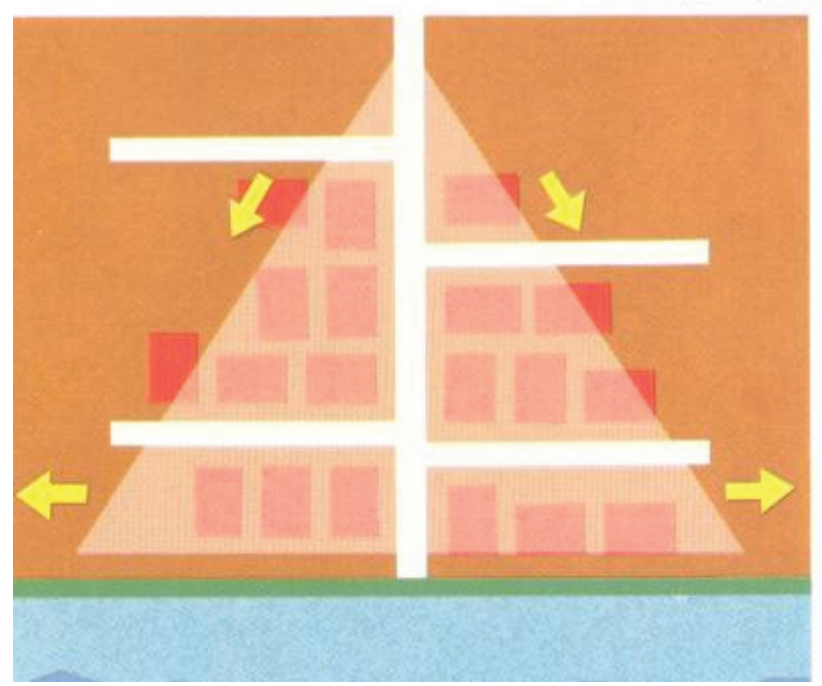

Situaçāo Pretendida/Desejada

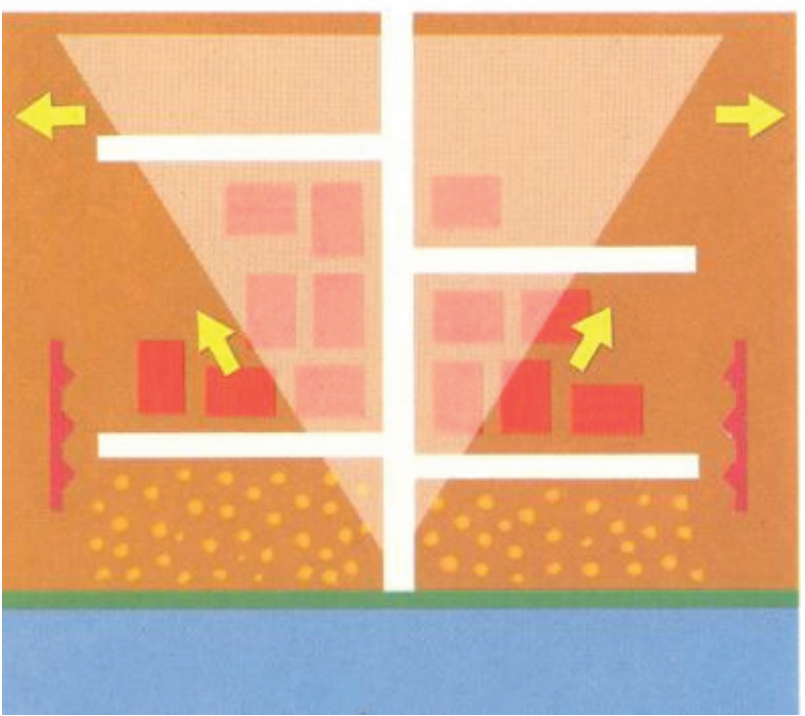

Fonte: INAG, 1994. 
Risco de erosão no litoral Norte de Portugal: uma questão de ordenamento do território António de Sousa Pedrosa

O sistemático recurso à artificializarão da costa, (figura 6) desacompanhado de qualquer monitorização dos seus efeitos, tem sido na prática o mecanismo de defesa e estabilização do litoral, apesar de a médio prazo, estas estruturas se revelarem não apenas vulneráveis a eventos marítimos mais energéticos, como também exigem ações recorrentes de reparação e manutenção bastante onerosas (CARDOSO, 2007). De fato, a intervenção humana no que respeita à problemática da erosão costeira tem sido feita na maioria das vezes de uma forma " $a d-h o c$ ", muito localizada e focalizada em dar resposta a situações de emergência, sem uma abordagem alargada, própria de um sistema heterogéneo, aberto e fortemente dinâmico.

Figura 6. A artificialização do litoral com a construção de obras de proteção em Cortegaça

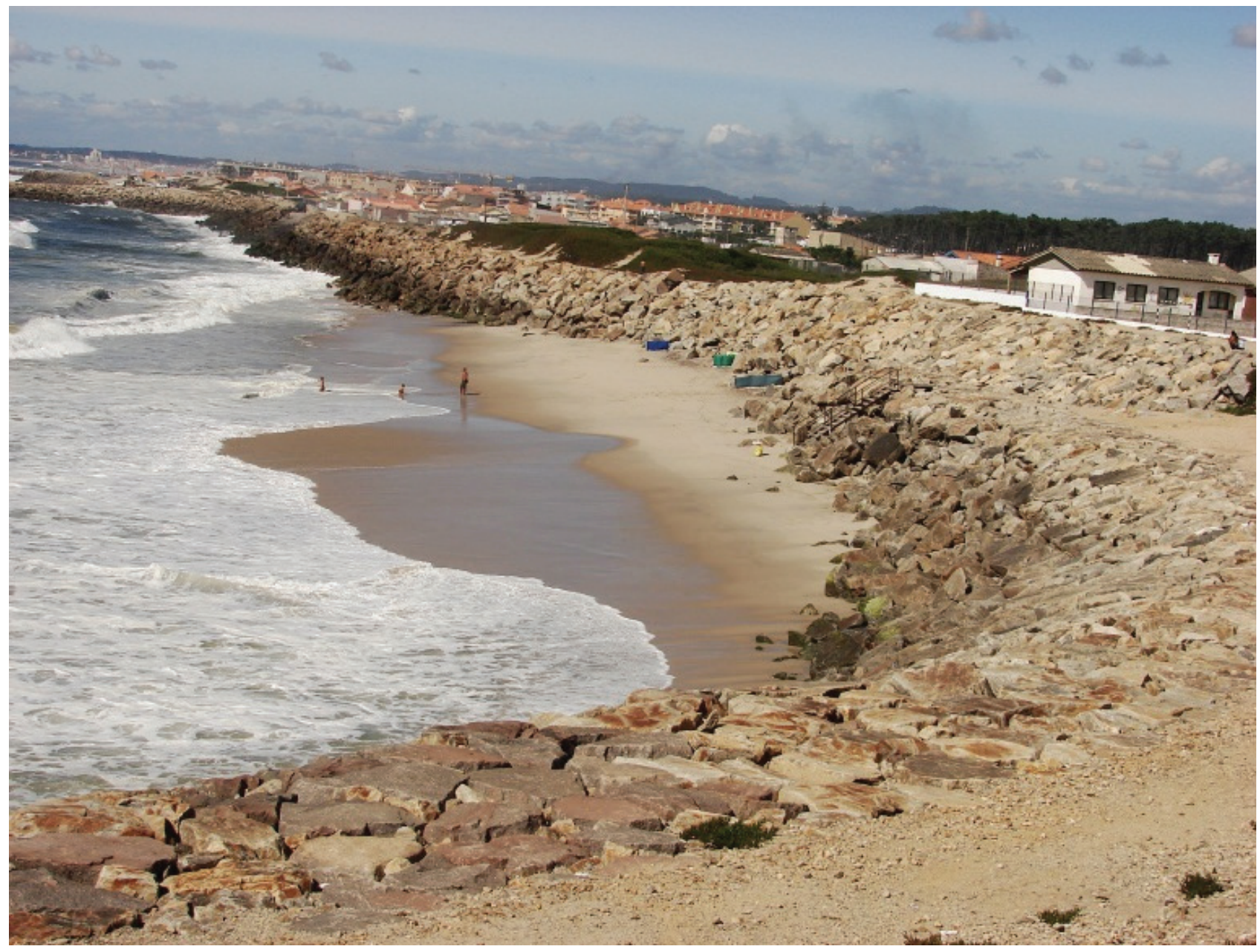

Fonte: Pedrosa, 2005.

Apenas na década de noventa surgem as primeiras tentativas de regulamentação e planeamento do litoral, com os Planos de Ordenamento da Orla Costeira (P.O.O.C.). Contudo, a gestão destes espaços litorais permanece, ainda, complexa e disseminada por vários agentes de atuação, que culmina numa dispersão e enfraquecimento de responsabilidades quando se trata de tomadas de decisão referentes ao ordenamento do território (figura 7). 
Figura 7. Sobreposição de planos de ordenamento na faixa litoral.

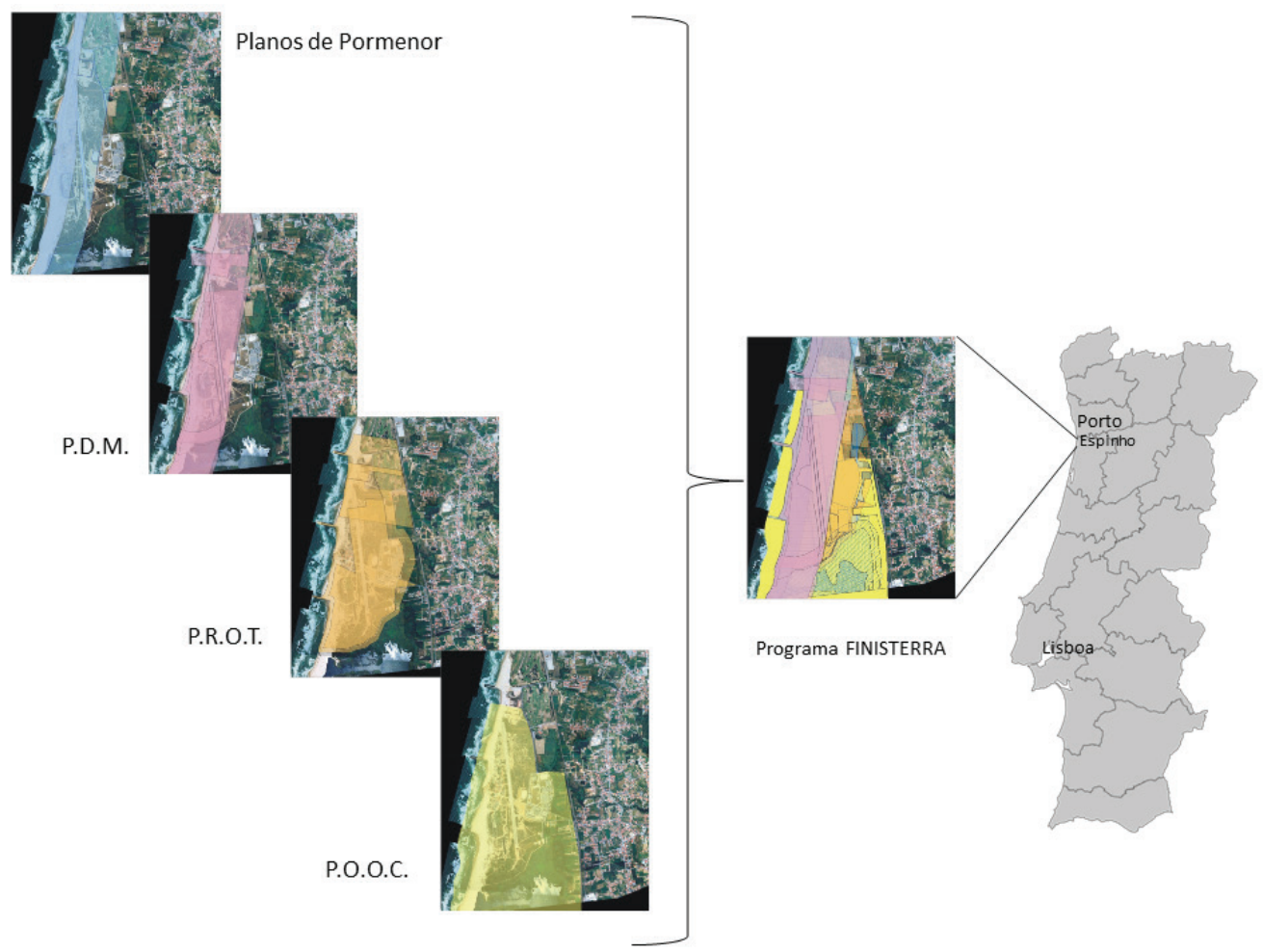

Fonte: A. Pedrosa et al, 2008

Esta intervenção enquadra-se legalmente em vários instrumentos de planeamento, decretos-lei, programas da Administração Central tais como:

Planos de Pormenor - documento oficial que avaliza a construção de infra-estruturas num município, definindo detalhadamente as regras de organização espacial do território de acordo com o Plano Director Municipal e com o Plano de Urbanização (Decreto-Lei n. ${ }^{\circ}$ 380/99, de 22 de Setembro, na redação dada pelo Decreto-Lei n. ${ }^{\circ} 310 / 2003$, de 10 de Dezembro e Despacho n. ${ }^{\circ}$ 6600/2004, de 23 de Fevereiro, do Secretário de Estado do Ordenamento do Território, publicado no DR n. ${ }^{\circ} 78$ (2 $2^{\mathrm{a}}$ série), de 1 de Abril);

P.D.M. - Plano Director Municipal é um instrumento de Ordenamento do Território de natureza regulamentar, em que a sua elaboração é obrigatória e da responsabilidade dos Municípios.
O P.D.M. tem como finalidade estabelecer o modelo de estrutura espacial, assente na classificação do solo, consubstanciando-se numa síntese da estratégia de desenvolvimento e de ordenamento local, integrando as opções e outros ditames de âmbito nacional e regional (Decreto de Lei 380/99 de 22 de Setembro da $1^{\text {a }}$ Série);

P.R.O.T. - Planos regionais de ordenamento do territóriosãoinstrumentosdecarácterprogramático e normativo visando o correto ordenamento do território através do desenvolvimento harmonioso das suas diferentes parcelas pela optimização das implantações humanas e do uso do espaço e pelo aproveitamento racional dos seus recursos. Os P.R.O.T abrangem áreas pertencentes a mais de um município, definidas quer pela sua homogeneidade em termos económicos, ecológicos ou outros, quer por representarem interesses ou preocupações que, pela sua interdependência, necessitam de 
consideração integrada (Decreto-Lei n. ${ }^{\circ}$ 338/83, de 20 de Julho);

P.O.O.C. - Os Planos de Ordenamento da Orla Costeira são planos setoriais que definem os condicionamentos, vocações e usos dominantes e a localização de infra-estruturas de apoio a esses usos e orientam o desenvolvimento das atividades conexas. Definem regras, não só relativas à praia, mas a toda a orla costeira, abrangendo tanto o domínio público marítimo como uma faixa de proteção terrestre com a largura máxima de 500 m. (Decreto-Lei n. ${ }^{\circ}$ 309/93 de 2 de Setembro);

> Programa FINISTERRA - Programa de Intervenção na Orla Costeira Continental que tem como objetivo coordenar todos os planos referidos anteriormente no espaço da orla costeira (Resolução do Conselho de Ministros n. ${ }^{\circ}$ 22/2003):

R.A.N. - Estabelece o novo regime jurídico da Reserva Agrícola Nacional. A vii) R.A.N., visa defender e proteger as áreas de maior aptidão agrícola e garantir a sua afetação à agricultura, de forma a contribuir para o pleno desenvolvimento da agricultura portuguesa e para o correto ordenamento do território (Decreto-Lei $\mathrm{n}^{\circ}$ 196/89 de 14 de Junho);

R.E.N. - A Reserva Ecológica Nacional, tem contribuído para proteger os recursos naturais, especialmente água e solo, para salvaguardar processos indispensáveis a uma boa gestão do território e para favorecer a conservação da natureza e da biodiversidade, componentes essenciais do suporte biofísico do território português (Decreto-Lei n. ${ }^{\circ} 321 / 83$, de 5 de Julho, modificado pelo DL 166 - 2008 de, 22 Agosto de 2008);

Planos de Bacia- Com os Planos de Bacia Hidrográfica pretende-se uma abordagem integrada das diversas matérias relacionadas como os recursos hídricos, incluindo nomeadamente as questões de natureza ambiental, e da observância do princípio da participação, envolvendo os diversos agentes interessados na gestão dos recursos hídricos (Decreto Lei n ${ }^{\circ}$ 45/94 de 22 de Fevereiro).

Apesar da existência de todas estas figuras legislativas a ação das entidades responsáveis pela gestão e ordenamento da faixa litoral é dificultada por diversas razões de que destacamos: $i$ ) jurisdições indefinidas ou dúbias quanto ás entidades responsáveis por decisões definitivas nesta área; $i i)$ a não coordenação entre os organismos da administração central que tutelam estas entidades; iii) problemas relacionados com a inadequação e desatualização da cartografia existentes para estas áreas.

Apesar de tudo, este tipo de regulamentação tem contribuído para inverter o estado de degradação em que se encontravam muitos sistemas dunares, notando-se uma série de intervenções de reabilitação e proteção dos mesmos.

\section{CONCLUSÃO}

Grande parte da costa noroeste de Portugal Continental compreende várias áreas em erosão acentuada, fato que tem vindo a contribuir para um agravamento da vulnerabilidade do território.

Esta situação resulta do fato do ordenamento do território nestas áreas litorais, nem sempre obedecer aos princípios de sustentabilidade ambiental e económica. Sendo áreas de forte sensibilidade à ação antrópica, em especial à pressão urbanística e à implantação de infraestruturas relacionadas com o turismo e o lazer, deveriam ter implicado a existência de planos de ordenamento, que tivessem definido uma estratégia de desenvolvimento não agressiva para as zonas de litoral em Portugal. Estes planos surgiram já numa fase muito avançada do processo de ocupação e degradação do litoral, debatendo-se com sérios problemas na sua implementação. Este fato resultou de, durante décadas, se ter verificado uma ocupação desordenada do território, que se aproximou cada vez mais da linha de costa, invadindo áreas de forte sensibilidade como os cordões dunares e, nalguns casos as próprias praias. A inexistência de uma estratégia bem definida de ordenamento territorial levou, então, em muitas situações, à destruição das dunas primá- 
rias aumentando naturalmente a vulnerabilidade das construções à dinâmica costeira, principalmente em situações de tempestade.

No sentido de proteger as povoações que avançavam cada vez mais em direção à linha de costa, iniciou-se a construção de estruturas pesadas de engenharia, que alteram significativamente as dinâmicas marítimas naturais revelando-se, cada vez mais, como uma fonte de problemas, do que uma forma de resolução dos processos erosivos provocado pelo avanço do mar. Há situações em que, pelo contrário, aceleram ainda mais esse mesmo processo.

As soluções que deveriam ter sido tomadas teriam de relacionar-se com o ordenamento do território de forma, por exemplo, a impedir a construção de estradas e edifícios (residenciais, comerciais ou outros), com o intuito de impedir o aumento da densidade do edificado e consequentemente da população e, deste modo, travar o aumento da vulnerabilidade e, como tal, os riscos associados ao avanço do mar. A solução não deveria ter sido de ordem estrutural, mas pelo contrário, deveria ter contemplado medidas não estruturais, ou seja, de caráter económico e sócio-ambiental, levando a uma desvalorização dos terrenos para a construção civil. Só desta forma se poderá a combater a especulação imobiliária, associada a chavões de marketing, tendo como tema âncora o mar, o litoral, as dunas... Se estas medidas tivessem sido tomadas de uma forma atempada, não encontraríamos tantas situações de risco elevado, como aquelas que se verificam no litoral NW de Portugal. Toda esta situação advém do caos legislativo, resultantes de sucessivas leis criadas no âmbito do ordenamento do território, mas que não tem em conta, a especificidade destes territórios. Não existe uma verticalização bem definida na figura legislativa sobre o litoral, o que permite várias interpretações e leva a várias situações de incumprimento da lei. Torna-se, cada vez, mais urgente uma tomada de decisão neste sentido, de forma a evitar situações futuras de incremento da vulnerabilidade e de maior risco.

Apresentando-se, a faixa costeira, como uma área de interface entre os subsistemas terra-mar, constitui-se como um espaço dotado de grande mutabilidade, que leva a um conflito constante, com o atual cariz permanente da presença humana, pelo que a fragilidade tem a sua maior expressão na erosão e no recuo da linha de costa, fenómeno que tem vindo a resultar na perda de áreas de valor ecológico-ambiental e económico.

O litoral NW português constitui uma zona com grandes potencialidades naturais e de uma riqueza de recursos inestimável (DIAS et al., 1994), ao longo de cerca de $103 \mathrm{~km}$ de extensão pelo que, enquanto espaço gerador de riqueza, move muitos interesses e procuras, que nas últimas décadas o transformaram num espaço frágil, cada vez mais degradado e em condições de difícil recuperação. É urgente, uma intervenção a nível legislativo, que regule eficazmente o ordenamento do território e evite mais intervenções de nível estrutural, extremamente dispendiosas quer, na sua construção quer, na sua conservação e com efeitos cada vez mais negativos na dinâmica natural do litoral.

Só um ordenamento eficaz do território pode evitar o aumento da vulnerabilidade relativamente ao processo acelerado de erosão do litoral NW de Portugal, cuja estratégia passa indiscutivelmente, por criar formas de não valorização dos espaços litorais, nomeadamente, no que se refere á possibilidade de construção de edifícios residenciais. Concluindo, podemos afirmar que muitas das situações de risco existente no litoral português, são claramente, uma questão de ordenamento do território.

\section{REFERÊNCIAS}

ARAÚJO, M. A. Depósitos Eólicos e Lagunares Fósseis na Região de Esmoriz, Revista da Faculdade de Letras - Geografia, série I, vol.1, Porto, pp. 5362, 1986.

ARAÚJO, M. A. Depósitos de fácies continental e marinho na plataforma litoral da região do Porto: importância da tectónica na sua organização espacial, Ciências da Terra (UNL), nº 14, Lisboa, p. 111-122, 2000.

ARAÚJO, M.A. Marine platforms from Oporto area (NW Portugal): Tectonics versus eustasy. Actas $d a \mathrm{~V}$ Reunião do Quaternário Ibérico, GTPEQ e AEQUA, Lisboa, p. 178-181, 2001. 
BARBOSA, J.et. al. Indicators of A Gis-Based Aerial Images Analysis of the Portuguese Northwest Coastal Dynamics, Faculdade de Engenharia da Universidade do Porto, 2003, 7 p.

BASTO, C. da M. F. P. Vulnerabilidade e risco face à erosão costeira entre Aguda-Paramos: duas metodologias de análise. Dissertação de Mestrado (Geografia Física), Faculdade de Letras, Universidade de Coimbra, Coimbra, 250 p., 2010.

CARDOSO, A. A. Padrões de Ocupação do Solo em Áreas de Risco natural : o caso do litoral Poveiro, dissertação de mestrado (Gestão de Riscos Naturais). Faculdade de Letras da Universidade do Porto, Porto, 192p., 2005.

. Litoral poveiro: perspectiva ambiental, Câmara Municipal da Póvoa do Varzim, Póvoa do Varzim, 158p., 2007.

CARVALHO, C. et al. Late Pleistocene and Holocene environmental changes in the coastal zone of northwestern Portugal. Journal of Quaternary Science, n'21, vol. 8, pp.859-877, 2006.

CARVALHO, G. S. et al. New Data and New Ideas Concerning Recent Geomorphological Changes in the NW Coastal Zone of Portugal". Actas do $6^{\circ}$ Simpósio Internacional-Littoral. The Changing Coast, EUROCOAST/ EUCC, Porto, Portugal, vol.2, pp. 399-410, 2002.

CARVALHO, G.; GRANJA, H.; LOUREIRO E. e HENRIQUES R. Late Pleistocene and Holocene environmental changes in the coastal zone of northwestern Portugal, Journal of Quaternary Science, 21 (8), p. 859-877, 2006.

CARVAlhO, J. J. R.; BARCELÔ, J. P. Agitação Marítima na Costa Oeste de Portugal Metropolitano - Contribuição para o seu Estudo. Memória no 290, Ministério das Obras Públicas, Laboratório Nacional de Engenharia Civil, Lisboa, 34 p., 1966.

COELHO, C. Riscos de Exposição de Frentes Urbanas para Diferentes Intervenções de Defesa Costeira, Tese de Doutorado, Universidade de Aveiro, 404p., 2005.

COSTA, M.; SILVA, R.; VITORINO, J. Contribuição para o Estudo do Clima de Agitação Marítima na Costa Portuguesa. In: 2AS. JORNADAS PORTUGUESAS DE ENGENHARIA COSTEIRA E PORTUÁRIA, Associação Internacional de Navegação - Sines. Anais..., 20 p., 2011.

DIAS, J. A. Dinâmica sedimentar e evolução recente da plataforma continental portuguesa setentrional: resumo, Gaia, 1, Lisboa, pp.34-36, 1989.

. A Evolução Actual do Litoral Português. Geonovas, Lisboa, 11:15-28, 1990.

Evolução da Zona Costeira Portuguesa: Forçamentos Antrópicos e Naturais, Encontros Científicos - Turismo, Gestão, Fiscalidade, 1, pp.7-27, 2005.

DIAS, J.A.; TABORDA, R. Evolução Recente do Nível Médio do Mar em Portugal, Anais do Instituto Hidrográfico, 9: 83- 97, 1988.

DIAS, J.A.; BERNARDO, P.; BASTOS, R. The Occupation of the Portuguese Littoral in 19th and 20th Centuries. Littoral 2002, Porto, vol. 3, 22-26, 2002.

DIAS, J.A.M.; FERREIRA, Ó. ; PEREIRA, A.R. Estudo Sintético de Diagnóstico da Geomorfologia e da Dinâmica Sedimentar dos Troços Costeiros entre Espinho e Nazaré. 1994, Edição electrónica (2005). Disponível em <http://w3.ualg.pt/ jdias/JAD/ ebooks>, acesso em dezembro de 2005.

GRANJA, H.M. Evidence for late Pleistocene and Holocene Sea-level, Neotectonic and Climate Control en the Coastal Zone of Northwest Portugal. Geologie en Mijnbouw, Kluwer Academic Publishers-Netherlands, 77, pp. 233-245, 1999.

LNEC. Instalação de uma Monobóia para Descarga de Petróleo Bruto para a Refinaria do Porto, Caracterização das Condições Naturais - Relatório Final. Relatório 172/96 - NPP, Laboratório Nacional de Engenharia Civil, Porto, 1996. 
MARTINS, V. et al. Holocene sea level changes recorded in the Galicia Muddy Deposits: contribution of geochemical data and radiocarbon dating. Memórias e Notícias do Museu e Laboratório de Mineralogia e Geologia. Coimbra, p.103-113, 2005.

PEDROSA, A. (Coord.). LITTORISK, Heritage and Prevention of Natural Hazards: Coastal Diffuse Habitats, Technical Report, Regional frame operation NoÉ. Heritage and Natural Hazards Prevention, Interreg III C Sud, Porto, 2007220 p. Disponível em $<$ http://www.pluridoc.com/Site/FrontOffice/default.aspx?module=Files/ FileDescription\& $\mathrm{ID}=2654 \&$ state $=\mathrm{SH}>$, acesso em dezembro de 2007.

PEDROSA, A. et al. Environmental impact of geomorphologic hazards in North Portugal coast. Geomorphic Hazards: Towards the prevention of disasters,- S7 Coastal Geomorphology and Hazard, IGU and Geomorphological Society of México, México, 1p., 2003, Disponível em : <http://www.pluridoc. $\mathrm{com} /$ Site/FrontOffice/default.aspx ?module=Files/ File Description $\& \mathrm{ID}=2617 \&$ state $=\mathrm{SH}>$, acesso em dezembro de 2003.
PEDROSA, A.; FREITAS, C. The human impact $\mathrm{n}$ the Espinho-Paramos coast in the 20th Century. Journal of Iberian Geology, 34 (2), p. 253-270, 2008a.

PEDROSA, A.; FREITAS, C. A vulnerabilidade do património classificado à erosão costeira no NW de Portugal: Contributo da geografia física. Geografia. Ensino \& Pesquisa. Santa Maria, p. 3468-3483, 2008b.

PEREIRA, A.; FREITAS, C. A Paisagem Litoral Portuguesa: Requalificação Ambiental ou Antropização Crescente?, comunicação apresentada. In: P E C S R L - THE PERMANENT EUROPEAN CONFERENCE FOR THE STUDY OF THE RURAL LANDSCAPE - 23rd Session "Landscapes, Identities and Development”, Annals... Lisboa, Óbidos, 2008.

RODRIGUES, A.; MAGALHÃES. F.; DIAS, J. Evolution of the North Portuguese coast in the last 18,000 years. Quaternary International. vol 9, pp. 67-74, 1991. 